\title{
Perpetuating Health Disparities of Minority Groups: The Role of U.S. Newspapers in the COVID-19 Pandemic
}

\author{
Zhan Xu' ${ }^{1} \cdot$ Carolyn A. Lin ${ }^{2} \cdot$ Mary Laffidy ${ }^{3}$. Lyndsey Fowks ${ }^{4}$
}

Accepted: 14 December 2021 / Published online: 21 January 2022

(c) Springer Science+Business Media, LLC, part of Springer Nature 2022

\begin{abstract}
During the COVID-19 pandemic, news media are expected to play a critical role in reducing health disparities. However, we know little about whether and how disparities in COVID-19 have been covered in national and local U.S. newspapers. This study examined whether minority health gained news attention and whether partisan bias affected related coverage in the early stages of the pandemic. Results indicate that minority groups have been underrepresented in COVID-19 news articles. Left-leaning newspapers were more likely to discuss minorities in COVID-19 news than least biased media. Left-leaning and right-leaning newspapers did not differ in the number of articles mentioning racial/ethnic minorities. COVID-19 news exceeded the average U.S. reading comprehension level and require some college education to understand but did not differ in readability levels among partisan newspapers. Left-leaning newspapers used significantly more medical terms and affiliated scientific facts to describe COVID-19 than right-leaning newspapers. Implications include avoiding potential failures in informing the public (especially the racial/ethnic minorities) essential scientific facts about disease prevention and increasing public trust in health news coverage.
\end{abstract}

Keywords COVID-19 $\cdot$ Newspapers · Disparities $\cdot$ Minorities

\section{Introduction}

As of this writing, the U.S has surpassed 621,000 COVID19 deaths and reached 36 million confirmed cases (COVID19 Dashboard, 2020). Communities of color from economically disadvantaged regions, relative to the rest to other racial groups, have been more heavily impacted by the severe health consequences from COVID-19 (Huang et al., 2020, 2021). Specifically, comparing to White Americans, the infection rate and fatality rate are respectively 1.7 and 2.4 times higher among Native Americans as well as 1.1 and 1.9 times greater among African Americans. Likewise, Hispanics or Latinos are 1.3 times more likely to become

\section{Zhan Xu}

zhan.xu@nau.edu

1 School of Communication, Northern Arizona University, 700 S. Knoles Dr, Flagstaff, AZ 86011, USA

2 University of Connecticut, Mansfield, CT, USA

3 University of Illinois at Urbana-Champaign, Champaign, IL, USA

4 Northern Arizona University, Flagstaff, AZ, USA infected and 2.3 times more likely to die from COVID-19, when compared to non-Latino Whites (CDC, 2020).

Health disparities refer to the "differences in health outcomes between groups and their causes among groups of people" (CDC, 2016). These differences result more from social determinants of health, such as social, economic, and political factors than from an individual's unhealthy behaviors (Adler \& Rehkopf, 2008). Among the major social determinants, communities and neighborhoods influence health outcomes and behaviors which lead to racial and ethnic health disparities. Reducing health disparities has been identified as a major priority in public health policy. However, the progress to address this issue has been slow in the U.S. (Bleich et al., 2012).

Increasing attention has been paid to communication about health disparities in the mass media (Niederdeppe et al., 2013). Early studies show that coverage of racial and ethnic health disparities was relatively scarce, representing $0.1 \%$ to $13.6 \%$ of all health news (Amzel \& Ghosh, 2007; Gollust et al., 2009; Rock, 2005; Taylor-Clark et al., 2007). For instance, racial disparities were only mentioned in $1 \%$ of health news stories from 2000 to 2004 (Amzel \& Ghosh, 2007). Less than one in seven diabetes related news articles mentioned racial disparities in 
a national sample of newspapers from 2005 to 2006 (Gollust et al., 2009). During the COVID-19 pandemic, news media are expected to play a critical role in reducing health disparities (Chowkwanyun \& Reed, 2020). However, few studies have assessed if mass media have effectively discussed racial and ethnic health disparities and if other factors, such as media partisan bias, have affected related coverage.

Prior research assessing news media coverage of issues related to health disparities often examined a small sample of news content within a specific media group (Niederdeppe et al., 2013), with most studies focusing on the coverage in national newspapers such as The New York Times (Gollust et al., 2009; Kim et al., 2010; Taylor-Clark et al., 2007). While national newspapers could provide a larger picture of the status and development of an issue or event in society, local news outlets are often the primary sources for national issues or events of local importance in local communities (Nagler et al., 2016). Specifically, local newspapers are regarded as the voices of community members and play a critical role in influencing regional public opinion and local policy (Paek et al., 2005; Viswanath et al., 2000). Health information delivered by local media is trusted by communities and influential, due to localization and community relevance (Caburnay et al., 2008; Cohen et al., 2008).

Mainstream news media are both the information disseminators and gatekeepers that determine what the audience sees or hear across digital and non-digital platforms (Lin, 2020). As indicated in a recent meta-analysis study, the effects of news media on influencing the perceived importance of issues and attributes in the public agenda remain stable in the digital environment to (Luo et al., 2019). This is evidenced by the fact that that $56 \%$ and $46 \%$ of the Americans polled in a national study respectively mentioned national and local news outlets as their major COVID-19 news sources, compared to 51\%, 36\% and $31 \%$ who considered public health organizations/officials, elected state/local officials and Trump/the coronavirus task force for the same, in that order (Shearer, 2020).

As COVID-19 has laid bare the severe consequences of health disparities in society, little to no empirical research has addressed how health disparities in relation to COVID19 have been covered in national and local newspapers. To address this empirical gap, the current study explored and compared the readability and use of medical terminology in COVID-19 news published in print and online partisan newspapers in the early stages of the pandemic.

\section{Literature Review}

\section{Health Disparities and Partisan Media}

Studies have found that mass media can raise the awareness of health disparities between certain groups
(Scheufele et al., 2002), increase the perceived issue importance, promote beliefs about social determinants of health (Niederdeppe et al., 2013) and policy support to reduce health disparities (Gollust et al., 2009), as well as encourage participatory action (Basu \& Dutta, 2009). Agenda setting and framing are often adapted to achieve these goals. Agenda-setting theory predicts that the quantity of health disparities discussed in the media can impact awareness and perceived salience of the issue. Framing theory suggests that different strategies used by the media to discuss health disparities can influence beliefs and attitudes regarding the issue (Niederdeppe et al., 2013). These studies tend to focus on the media effects on individual attitudes and behaviors (Viswanath \& Emmons, 2006).

Other studies take a structural approach with the assumption that agencies, groups, individuals within the media, and audiences all influence media messages. This approach contends that mass media content often reflects the existing systemaic inequality and may ignore or downplay health disparities (Viswanath \& Emmons, 2006). However, the way structural factors influence media content could differ across various media (Niederdeppe et al., 2013). Specifically, partisan lean is one of the major structural factors that could influence media bias, which has been found to impact the awareness of health disparities and the acceptance of social determinants of health (Booske et al., 2011; Gollust \& Cappella, 2014; Gollust et al., 2009). Partisan media bias refers to systematically favoring one party over others in news reporting (Groeling, 2013). This type of media bias tends to downplay or ignore negative stories about the media outlet's favored parties, while highlight or exaggerate negative stories about their disliked parties (Puglisi \& Snyder, 2011). In addition to political, economic, and social news, partisan media bias also emerges in issues that seemingly should not be polarized, such as public health (Baum, 2011; Larcinese et al., 2011; Merkley, 2019).

According to the structural approach of media effects, media audiences choose, trust, and react to media content, based on their communities and social roles (Viswanath \& Emmons, 2006). Media audiences' political attitudes heavily impact partisan media bias (Gentzkow \& Shapiro, 2011), aside from media ownership (Balan et al., 2011) and reporters' own political party inclination (Baron, 2006). Based on the media's target audience, some news sources may regard racial and ethnic health disparities as more newsworthy, while other sources may consider such topics lacking audience interest (Cohen et al., 2008; Lumpkins et al., 2010; Stryker et al., 2009). For instance, according to the Pew Research Center, Democrats and Democratic leaners are more likely to regard racial equality as a critical issue than Republicans and Republican leaners (Pew Research Center, 2017). 
Since Americans prefer media sources that are consistent with their own partisan perspective (Pew Research Center, 2020), right-leaning media may not perceive racial/ethnic health disparities as important as left-leaning media, and thus may not cover as many related stories. This may lead to a vicious circle where conservative audiences are less likely to be exposed to health disparities news contents, relative to their liberal counterparts. As a result, conservatives were $30 \%$ less likely to be aware of racial health disparities (Booske et al., 2011).

In the current study context, left-leaning media may similarly cover more stories related to COVID-19 health disparities than right-leaning media. For instance, a nationally representative survey shows that Democrats and those who are exposed to left-leaning national news are more likely to recognize health disparities issues (Gollust et al., 2020).

To further validate the limited literature on the potential relationship between partisan media and their coverage of health disparities issues, the following hypothesis was proposed.

H1a Left-leaning newspapers are more likely than rightleaning newspapers to publish COVID-19 news stories about minority groups.

H1b Left-leaning newspapers are more likely than rightleaning newspapers to publish COVID-19 news stories about African Americans.

H1c Left-leaning newspapers are more likely than rightleaning newspapers to publish COVID-19 news stories about Hispanics or Latinos.

H1d Left-leaning newspapers are more likely than rightleaning newspapers to publish COVID-19 news stories about Asian.

H1e Left-leaning newspapers are more likely than rightleaning newspapers to publish COVID-19 news stories about Native Americans.

\section{Health Disparities and Health Information Readability}

Social groups may differ in their abilities to access, use, and act on information, which is referred to as communication inequality. Communication inequality may result from a lack of understanding of the message or capacity to act on it (Viswanath \& Emmons, 2006). In health communication, limited health literacy often results in a limited understanding of health information. Health literacy is "the degree to which individuals have the capacity to obtain, process, and understand basic health information and services needed to make appropriate health decisions" (U.S. Department of Health and Human Services, 2010). Minority communities often have limited health literacy, which may lead to worsened health conditions, limited health knowledge, less use of preventive measures, and higher hospitalization and death rates (Institute of Medicine, 2004). The Covid-19 pandemic has also exposed the health disparities among a large percentage of racial and ethnic minorities who have inadequate access to health services, low health literacy and high rates of chronic diseases (Ronald \& Morial, 2020; Zanolli, 2020).

To ensure minority communities and low-literacy readers understand health information, the U.S. National Institutes of Health (NIH) has a set of guidelines for assessing the readability of health education materials. Readability measures how difficult the text is to read and is often calculated by schooling levels (e.g., fifth-grade reading level). Lower readability indicates that the text is more difficult to understand. Lexical and syntactic features both contribute to how readable the text is (Crossley et al., 2017; Tausczik $\&$ Pennebaker, 2010). The average reading comprehension level is the seventh grade in the U.S.

The American Medical Association (AMA) and the National Institutes of Health (NIH) recommend that health information targeting patients should not exceed the sixthgrade reading level. Average U.S. adult reading skill is around the eighth-grade level (Eltorai et al., 2014). Based on the target population, health information should be two to five grades lower than their highest grade of education since reading skills tend to decline over time (NIH, 2016). When targeting minority communities and low-literacy readers, the readability of health education materials should not exceed fifth-grade reading levels (D'Alessandro et al., 2001; C. A. Lin et al., 2009; Stossel et al., 2012).

Health information constructed for lower reading levels can assist information processing and understanding (Freidman \& Tanner, 2007; French \& Larrabee, 1999). However, in reality, health education materials are often produced for a higher reading level. For instance, roughly $80 \%$ of cancer resources exceed 10th grade reading level (Thomson \& Hoffman-Goetz, 2007) and most pediatric patient education materials are at the 12th grade reading level (D'Alessandro et al., 2001). More than $60 \%$ of online human papillomavirus (HPV) related information can only be understood by college students or graduates (Xu et al., 2019). Through the evaluation of 7891 health websites, a meta systematic review concluded that online health information in the U.S. was too difficult for most people to read (Daraz et al., 2018). These findings indicate that these health messages exceed most viewers' reading capacity and may not be helpful in promoting healthy behaviors (Walsh et al., 2008).

According to the CDC's guideline for health literacy, health professionals and the media often have a misapprehension about and hence unattainable expectations of their 
target audience's reading comprehension skills and health/ medical knowledge (CDC, 2009). As a result, they may create health messages that are difficult to read or contain technical and medical terminology. For instance, instead of "heart," many health messages use the medical term "cardiovascular," which is hard to understand for many people (CDC, 2009). Both the CDC and NIH recommend replacing jargon and medical terms with plain language to ensure health messages and programs are easy to comprehend (Everyday Words for Public Health Communication, 2016; NIH, 2016). For example, instead of using the term "bacteria," message designers should use "germs" or "bugs." "Contagious" should be explained as "germs can spread from one person to another" (CDC, 2016). Studies have shown that when exposed to more vocabulary choices, viewers' comprehension of health messages can improve over time (Sakai, 2013).

Limited studies have examined readability and the use of medical terminology in health news. General reviews of the news show that news articles tend to be difficult to understand and are increasingly less readable, since news articles prefer to include longer words, sentences, and more complicated grammatical structures (Dalecki et al., 2009). However, since mass media, especially newspapers, are a critical information gatekeeper in disseminating the news stories that could help prevent, contain or even eliminate infectious diseases (Tchuenche \& Bauch, 2012; Xu et al., 2020), it is important to assess if existing health news coverage is effective in reaching the target audience. In particular, previous empirical studies have validated the effects of newspapers on the public's perception of and vaccination decision-making regarding other infection diseases. For example, past research found that exposure to newspapers was effective in shaping risk perception of the H1N1 virus and vaccination intention (C. A. Lin \& Lagoe, 2013). Another research discovered that newspapers discussing flu vaccination shortages successfully promoted earlier vaccination (Yoo et al., 2010).

The extant literature has yet to explore whether health news published by various partisan media differ in terms of readability and the use of medical terms. In the current study context, it is reasonable to speculate that news sources with a different political leaning may perceive the newsworthiness of a topic such as health disparities differently (Cohen et al., 2008; Lumpkins et al., 2010; Stryker et al., 2009). For this reason, it is possible that partisan-leaning newspapers may cover health disparities with varying approaches that could influence the readability of their published stories. To explore these assumptions, we asked the following research questions:
RQ1 Do COVID-19 news articles published by left-leaning, least biased, and right-leaning media reflect different readability levels?

RQ2 Do COVID-19 news articles published by left-leaning, least biased, and right-leaning media contain different amounts of medical terminology?

\section{Methods}

\section{Data Collection}

Our sample consisted of news articles about COVID-19 published in national and local U.S. print and online newspapers from January 21, 2020 through June 30, 2020. The first recorded coronavirus case in the U.S. was on January 21, 2020 (First Travel-related Case of 2019 Novel Coronavirus Detected in United States, 2020). During this 6-month period, we also saw the first wave of the pandemic, which peaked in April (Akinbami et al., 2020). We first collected all new articles in Lexis-Nexis that contained any of the terms in their headlines, including "COVID", "coronavirus", "corona", or "SARS". The sample included 27,269 articles published in 66 newspapers. We then searched the partisan bias score of each newspaper obtained from the first step in the Media Bias/Fact Check (MBFC) database. Newspapers without partisan bias score were excluded from the final analysis. The final sample included a total of 24,345 articles published in 40 newspapers (Appendix A).

\section{Measures}

\section{Partisan Newspapers}

We obtained each newspaper's partisan bias score from MBFC, which is an independent outlet that calculates media sources' partisan bias based on criteria such as endorsed political ideology, one-sided versus two-sided covering, source credibility, and biased wording. MBFC categorized all the newspapers in our sample into left-leaning, least biased, and right-leaning biases. MBFC has been repeatedly used and validated in previous studies (Nørregaard et al., 2019; Stefanov et al., 2020).

\section{Racial and Ethnic Descriptors}

These included specific racial and ethnic group terms (e.g. Latino) and general group terms (e.g. Minority) (Appendix B). These terms were adapted from previous health disparities studies (Bhopal, 2004; Kim et al., 2010). 


\section{Readability}

SMOG (Simple Measure of Gobbledygook) was used to assess readability (McLaughlin, 1969). SMOG predicts readability based on "the number of polysyllabic words (words with more than 3 syllables) and the number of sentences" (Zheng \& Yu, 2017). It directly generates ordinal grade level of an article and calculates its readability on a continuous scale starting from grade four. Grade 13 to grade 15 is college level. Grade 16 or higher is college graduate level (McLaughlin, 1969). SMOG was the only one readability formula recommended by the NIH in its "Clear Communication" guideline to estimate the reading level of health information (NIH, 2016) and was regarded as the most consistent reading level measure (Wang et al., 2013).

\section{Medical Terminology}

was measured using the R package "healthforum." The package contained medical dictionaries from physician and medical documentation software developer as well as medical spell checker software (Hu \& Kearney, 2019).

\section{Analysis}

The R (version 4.0.2) software package was utilized for all the analyses. We first calculated the number of articles with at least one racial and ethnic descriptor published by each newspaper. Then, Kruskal-Wallis test was used to compare the number of published articles that contained at least one racial and ethnic descriptor across left-leaning, right leaning, and least biased newspapers.
Finally, readability and the amount of medical terms were compared among articles published by left-leaning, least biased, and right-leaning using Kruskal-Wallis test. Benjamini-Hochberg method was used to adjust $\mathrm{p}$-values for multiple comparison in post-hoc Wilcoxon rank sum test.

\section{Results}

A total of 12, 650 articles were published in left-leaning newspapers. Least biased newspapers published 4884 articles. Right-leaning newspapers published 6811 articles. Among all 24,345 news articles in our sample, 4206 (17.28\%) included at least one racial and ethnic descriptor (Median =0, Range: 0-106). H1a asked whether left-leaning media were more likely to publish COVID-19 news about general minorities than right-leaning media. Results demonstrated that partisan newspapers significantly differed in the number of articles containing at least one racial and ethnic descriptor. Specifically, left-leaning newspapers published significantly more COVID-19 related articles containing at least one racial and ethnic term than least biased newspapers. Right-leaning newspapers did not differ in the number of articles containing at least one racial and ethnic descriptor from left-leaning or least biased newspapers (Fig. 1). Detailed information can be found in Table 1. Thus, H1a was not supported.

Regarding each specific racial and ethnic group, 1985 $(8.15 \%)$ news articles included at least one reference of African Americans. Partisan newspapers significantly differed in the number of articles containing at least one term referring to African Americans. Specifically, significantly more leftleaning newspapers published COVID-19 related articles containing at least one description of African Americans than least biased newspapers. Right-leaning newspapers did
Fig. 1 Number of COVID-19 news articles containing at least one racial and ethnic descriptor in partisan newspapers

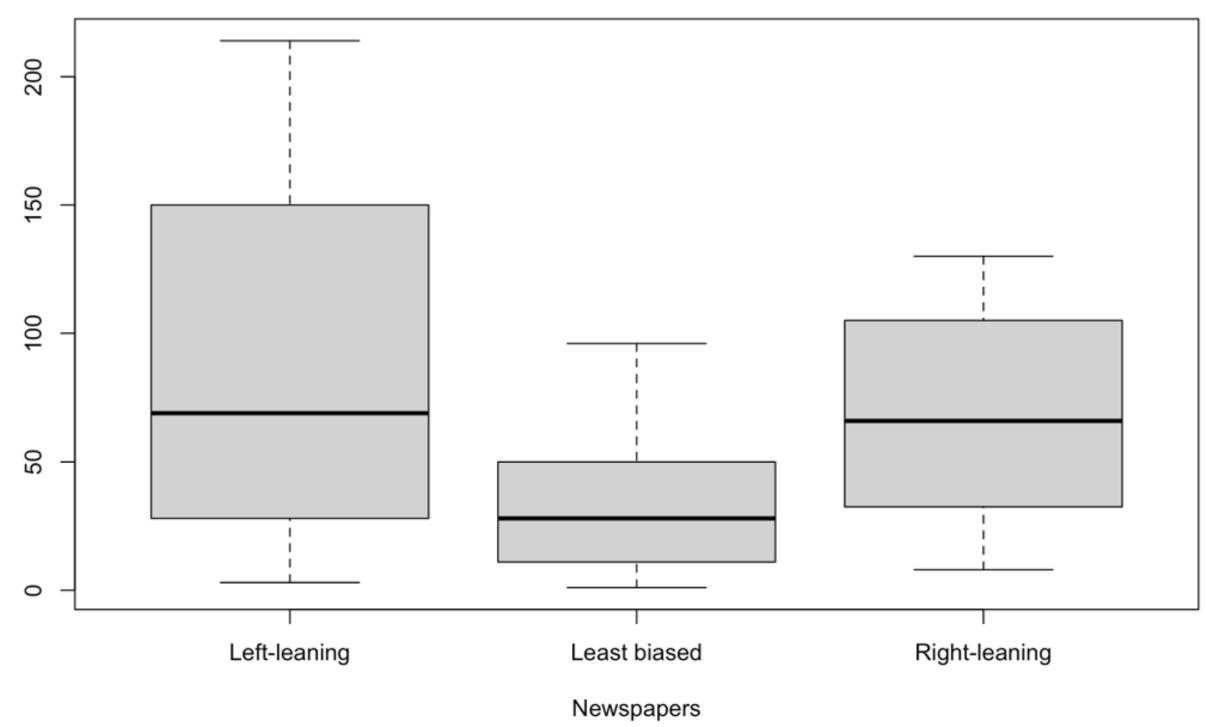


Table 1 Number of COVID-19 minority news articles published by partisan newspapers

\begin{tabular}{|c|c|c|c|c|c|c|c|c|}
\hline \multirow[b]{2}{*}{$\begin{array}{l}\text { Racial/ethnic } \\
\text { descriptor }\end{array}$} & \multirow[b]{2}{*}{$\begin{array}{l}\text { Articles } \\
(N=24,345) \\
\mathrm{N}(\%)\end{array}$} & \multicolumn{3}{|c|}{$\begin{array}{l}\text { Median of articles containing at least one } \\
\text { racial/ethnic descriptor }\end{array}$} & \multirow{2}{*}{$\begin{array}{l}\text { Kruskal-Wal- } \\
\text { lis rank sum } \\
\text { test }\end{array}$} & \multicolumn{3}{|c|}{ Post-hoc Wilcoxon rank sum test } \\
\hline & & Left-leaning & Least biased & Right-leaning & & $\begin{array}{l}\text { Left vs. right- } \\
\text { leaning }\end{array}$ & $\begin{array}{l}\text { Left-leaning } \\
\text { vs. least biased }\end{array}$ & $\begin{array}{l}\text { Right vs. least } \\
\text { biased }\end{array}$ \\
\hline $\begin{array}{l}\text { General } \\
\text { Minorities }\end{array}$ & $4206(17.28 \%)$ & 69 & 28 & 66 & $\begin{array}{c}\chi^{2}=6.76, \\
\mathrm{df}=2, \\
p=0.03\end{array}$ & $\begin{array}{c}z=0.30 \\
\text { adjusted } \\
p=0.77\end{array}$ & $\begin{array}{c}z=2.49 \\
\text { adjusted } \\
p=0.04\end{array}$ & $\begin{array}{c}z=-1.89 \\
\text { adjusted } \\
p=0.09\end{array}$ \\
\hline $\begin{array}{l}\text { African } \\
\text { American }\end{array}$ & $1985(8.15 \%)$ & 39 & 11 & 24 & $\begin{array}{c}\chi 2=6.55 \\
\mathrm{df}=2, \\
p=0.04\end{array}$ & $\begin{array}{c}z=0.18 \\
\quad \begin{array}{l}\text { adjusted } \\
p=0.86\end{array}\end{array}$ & $\begin{array}{c}z=2.42, \\
\quad \begin{array}{l}\text { adjusted } \\
p=0.05\end{array}\end{array}$ & $\begin{array}{c}z=-1.97 \\
\text { adjusted } \\
p=0.07\end{array}$ \\
\hline $\begin{array}{l}\text { Latino/His- } \\
\text { panic }\end{array}$ & $441(1.81 \%)$ & 8 & 4 & 8 & $\begin{array}{c}\chi^{2}=4.28, \\
\mathrm{df}=2, \\
p=0.12\end{array}$ & - & - & - \\
\hline Asian & $706(2.90 \%)$ & 6 & 3 & 6 & $\begin{array}{c}\chi^{2}=3.07 \\
\mathrm{df}=2, \\
p=0.21\end{array}$ & - & - & - \\
\hline $\begin{array}{l}\text { Native Ameri- } \\
\text { can }\end{array}$ & $712(2.92 \%)$ & 13 & 4 & 15 & $\begin{array}{c}\chi^{2}=5.82, \\
\mathrm{df}=2, \\
p=0.054\end{array}$ & - & - & - \\
\hline
\end{tabular}

not differ from left-leaning or least biased newspapers. Thus, H1b was not supported.

A total of $441(8.15 \%)$ news articles included at least one descriptor referring to Hispanics/ Latinos. Partisan newspapers did not significantly differ in the number of articles containing at least one term referring to Hispanics/ Latinos. Thus, H1c was not supported. A total of 706 (2.90\%) news articles included at least one mention of Asians. Partisan newspapers did not significantly differ in the number of articles containing at least one reference of Asian. Thus, H1d was not supported. A total of 712 (2.92\%) news articles included at least one term referring to Native Americans. Partisan newspapers did not significantly differ in the number of articles containing at least one description referring to Native Americans. Thus, H1e was not supported.

RQ1 asked if COVID-19 news articles published by partisan newspapers differed in readability levels. The median readability of all COVID-19 related news articles was 14.99 (Range: 7.39-66.49). Kruskal-Wallis test revealed that news articles published in left-leaning (Median=14.9), least biased $($ Median $=16.3)$, and right-leaning $($ Median $=13.2)$ newspapers did not significantly differ in readability levels $\left(\chi^{2}=5.32, \mathrm{df}=2, p=0.07\right)$ (Fig. 2).

RQ2 questioned whether COVID-19 news articles published by partisan newspapers differed in the amounts of medical terms. The median number of medical terms in all
Fig. 2 Readability levels of COVID-19 news articles published by partisan newspapers

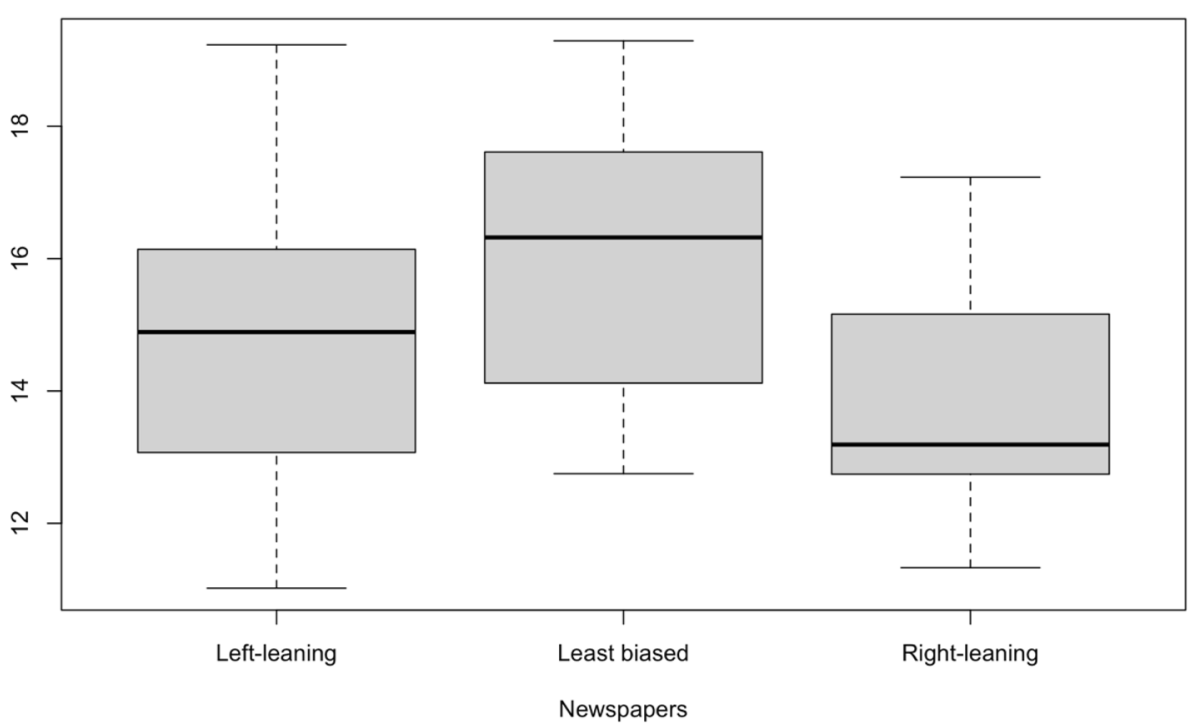


COVID-19 related news articles was 124 (Range: 0 - 4,541). Results indicated that news articles published in partisan newspapers contained a significantly different number of medical terminology $\left(\chi^{2}=8.12, \mathrm{df}=2, p=0.02\right)$. Specifically, articles published in left-leaning newspapers included significantly more medical terms $($ Median $=129)$ than articles published in right-leaning newspapers $($ Median $=98$, $z=2.71$, adjusted $p=0.02$ ). Articles published in least biased newspapers did not contain a significantly different number of medical terms than articles published in leftleaning $(z=1.88$, adjusted $p=0.09)$ or right-leaning newspapers $(z=0.90$, adjusted $p=0.37)$ (Fig. 3 ).

\section{Discussion}

This study reveals that up to $17.28 \%$ of COVID-19 news articles mentioned racial and ethnic groups. Left-leaning newspapers were more likely to discuss minorities in COVID-19 news than least biased media. However, left-leaning and right-leaning newspapers did not differ in the number of articles mentioning minorities. Partisan newspapers did not differ in the number of articles describing each specific racial and ethnic group. Furthermore, the median readability of all COVID-19 related news articles across left-leaning, right-leaning and least-based newspapers was 14.99. Partisan newspapers did not differ in readability levels. Leftleaning media used significantly more medical terms than right-leaning media.

Compared to prior research findings which indicate that $0.1 \%$ to $13.6 \%$ of health news discuss racial and ethnic health issues unrelated and prior to the COVID-19 concern (Amzel \& Ghosh, 2007; Gollust et al., 2009; Rock, 2005; Taylor-Clark et al., 2007), the $17.28 \%$ of Covid-19 coverage of minorities indicates an improvement in the amount of news space given to racial minority concerns. As individuals classified as Black/African, Hispanic, Asian, and Native Americans represent $13.4 \%, 18.5 \%, 5.9 \%$ and $1.3 \%$ of the U.S. population (U.S. Census Bureau, 2019), the COVID19 news coverage that mentioned each of these racial/ethnic group stood at $8.15 \%, 8.15 \%, 2.9 \%$ and $2.92 \%$, respectively. This suggests that the voice of each of these groups in relation to the COVID-19 pandemic might have been underrepresented in these newspapers, except for the Native American group.

Compared the current study findings to past research results that addressed the perceived coverage of minority health issues in the news, it is clear that news attention to minority health issues is similarly lacking. For example, results from a national phone survey showed that $71 \%$ of African Americans felt that stories from general news networks (outlets not created for Black communities) catered to White audiences and only $27 \%$ believed these networks adequately covered health threats specific to Black communities (Brodie et al., 1999). Prior research also indicated that news coverage about minority health issues tended to emphasize "individual-oriented causal attributions," blaming individual behaviors and lifestyle for health problems (Niederdeppe et al., 2013).

Combining the current findings of disproportionally limited COVID-19 news coverage of racial/ethnic communities and existing community perceptions of underrepresentation
Fig. 3 Number of medical terms contained in COVID-19 news articles published by partisan newspapers

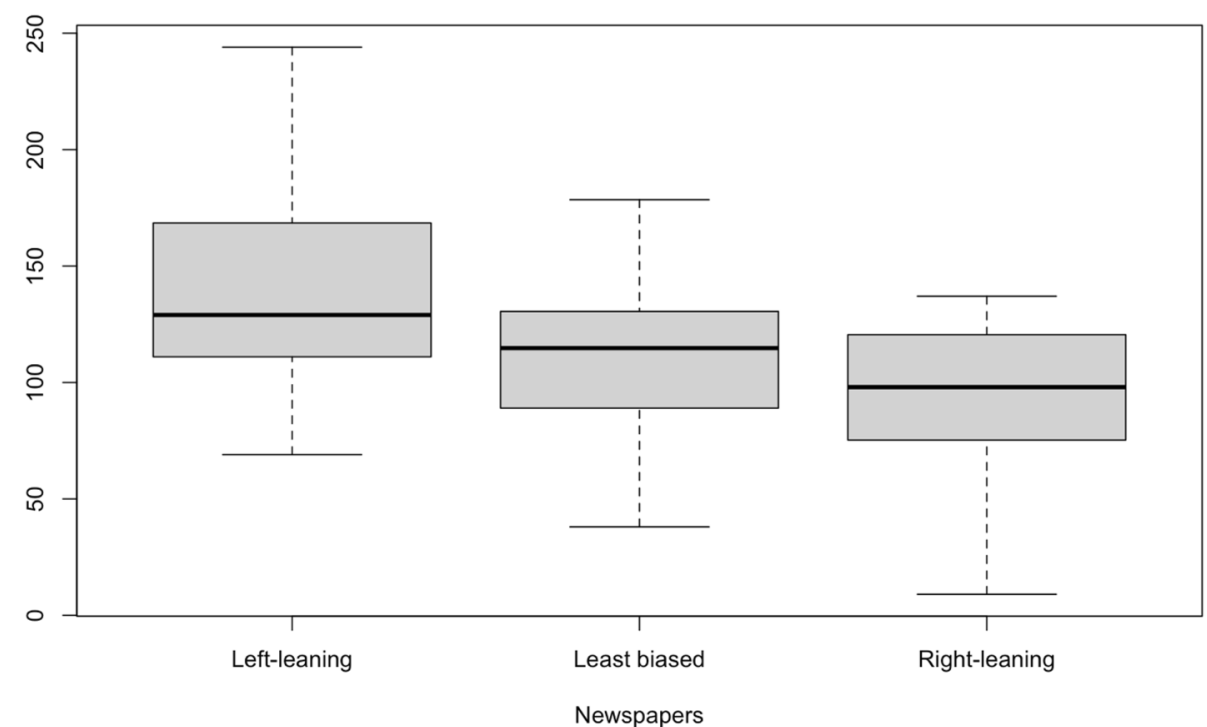


in major news media and the attribution of individual blame, it is possible that news coverage of COVID-19 will not gain a high-level of trust in these communities. A lack of trust in the news coverage then could lead to low efficacy in adopting preventive measures, including vaccine uptake (L. Lin et al., 2014), even though newspapers were found to have an influence on pandemic risk perception and vaccination intention (Lin \& Lagoe, 2013). The lack of minority representation in the study sample did not differ between right- vs. left-leaning newspapers. It is possible that when the COVID-19 related stories did mention selected minority groups, the relevant discussion might have been presented to target primarily the majority White audiences who tend to be heavier consumers of mainstream newspapers (AlamoPastrana \& Hoynes, 2020). Hence, whether the underrepresentation of minorities in health news coverage amounts is due to readership and circulation factors or the "individual-blame" related racial/ethnic bias, there appears to be a systemic under reporting of minority health issues in the news media. Future studies should further investigate this systemic problem to better understand whether newspapers and news media in general, regardless of their political leaning, provide sufficient coverage of minority health issues to avoid undermining the improvement and protection of the health status of minority communities.

Our finding also revealed that least-biased newspapers published fewer articles about racial and ethnic groups than left-leaning newspapers. It is possible that when the leastbiased newspapers published news stories about COVID-19, they tended to shy away from mentioning racial and ethnic minorities to avoid appearing partisan. Prior research on this topic argues that such extraneous efforts to remain objective marginalizes journalists (and people) of color, while upholding white experiences as standard, neutral mediums for information sharing (Alamo-Pastrana \& Hoynes, 2020). Additional research is needed to explore the individual and structural factors that drive the newsroom and editorial decisions on how report minority health issues which are inherently related to health disparities and have been politicized.

Turning to the results of readability of the COVID-19 news coverage, all COVID-19 news articles in the study sample exceeded the average U.S. reading comprehension level. To understand these COVID-19 stories, it would require the audience to have at least some college education. These findings suggest that national and local newspapers in the U.S. might not have taken into consideration those readers with low reading and health literacy levels, when reporting on health-related topics that involve a certain level of science and health literacy above and beyond reading comprehension level. As a primary information source for local communities (Caburnay et al., 2008; Cohen et al., 2008; Nagler et al., 2016), local newspapers could play a critical role in developing and disseminating readable health information through their news coverage on a localized presentation of COVID-19 related infection rates, health consequences, preventive measures, vaccination needs, fatality rates and more that address the information needs of both the general, vulnerable and minority populations.

Though left- and right-leaning newspapers did not differ in the reading levels affiliated with their COVID-19 news articles, left-leaning media tended to use more medical terms than right-leaning media. Specifically, COVID19 news articles published in left-leaning newspapers contained about 30 more medical terms on average than those published in right-leaning counterparts. It is possible that in its desire to provide science-based information to establish the credibility of the COVID-19 stories, the leftleaning newspapers chose to use more medical terms and affiliated scientific facts to describe and analyze the issues at stake than right-leaning newspapers.

Previous studies have demonstrated the importance of using medical terminology in health messages. Information seekers may depend on heuristics cues to make decisions quickly. They may evaluate the quality and credibility of a message based on superficial factors, such as terminology, article length, etc. (Hilligoss \& Rieh, 2008; Metzger \& Flanagin, 2013; Sundar, 2008). Most viewers skip commonly used words but focus on unfamiliar and difficult terms (Rayner et al., 2011). Health information with more technical terms is regarded as more credible and professional and thus are more engaging and convincing (Kao, 2013; Xu, 2020).

To circumvent the challenge of using necessary but unfamiliar medical terms in presenting health news coverage to their readers, it could be useful for journalists to provide a description to explain those terms and their related medical facts. In particular, this description needs to be written in a simple, concise and straightforward style to enable an individual with a fifth-grade reading level to easily grasp the meaning of the description. Future work can assess the effectiveness of utilizing different combinations of medical terminology and reader-friendly explanations to communicate science-based information, in conjunction with eliciting heuristic responses to such information to facilitate health knowledge gains. 
The fact that the left- and right-leaning newspapers did not differ significantly in their mention of racial/ethnic minorities or the readability level in their published COVID-19 stories suggests that, these newspapers had performed their journalistic function - as evaluated with these two criteria - without injecting a statistically discernible level of partisanship. In sum, more research is needed to assess how health-related news is presented to the general public and the racial/ethnic minorities (including the readability level) to reduce the health information disparities within and between each constituency.

Such research will help us gain a better understanding of the multiple social and economic implications associated with the influence of science journalism. These implications could include avoiding potential failures in informing the public (especially the racial/ethnic minorities) essential scientific facts about disease prevention and increasing public trust in health news coverage. By performing both of these two important journalistic functions well to help improve or safeguard public health, the newspaper industry could also help enhance its ability in maintaining reader loyalty and circulation level.

\section{Limitations and Conclusion}

Several study limitations should be noted here. First, the focus of this research was to examine whether COVID-19 health concerns associated with racial and ethnic minorities gained news attention in the newspapers and whether such news attention differed among newspapers with different political leaning. As this study only examined print and online newspapers, results may not be generalizable to other media sources such as social media and television news. Furthermore, the Lexis-Nexis database does not include all newspapers published in the U.S. This means that our sample may not be fully reflective of the entire scope of leftleaning, right-leaning, or the least-biased newspapers in the U.S. across different market sizes and geographic regions. Finally, this study only explored COVID-19 news articles published in the early stages of the pandemic and did not fully reflect the entire scope of U.S. newspapers covering health disparities during the pandemic. It is interesting to examine whether left-leaning, rightleaning, or the least-biased newspapers pay more attention to minority health as the pandemic evolves and whether they change their strategies to report health disparities. It is possible that one group of partisan media may increase their coverage of minority health more drastically compared to other partisan media as the pandemic continues and thus may result in a significant difference in the rate at which minority health was discussed in related content. Future studies can also benefit from comparing COVID19 news articles across different phases of the pandemic.

\section{Appendix A}

See Table 2.

Table 2 Newspapers included in this study

Anchorage daily news

Arizona Capitol Times

Bangor Daily News

Daily Herald

Daily News

Daily Record

Dayton Daily News

Deseret Morning News

LNP

Los Angeles Times

New York Observer

Orange County Register

Pittsburgh Post-Gazette

Providence Journal

Richmond Times Dispatch

South Bend Tribune

Spokesman Review

St. Louis Post-Dispatch

Star Tribune

Tampa Bay Times

The Atlanta Journal-Constitution

The Baltimore Sun

The Bismarck Tribune

The Daily News of Los Angeles

The Daily Oklahoman

The Hartford Courant

The Hill

The Lebanon Daily News

The Morning Call

The New York Post

The New York Times

The Pantagraph

The Philadelphia Inquirer

The Salt Lake Tribune

The San Diego Union-Tribune

The Santa Fe New Mexican

The Washington Post

Tribune-Review

Wall Street Journal

Wisconsin State Journal 


\section{Appendix B}

See Table 3.

Table 3 Racial/ethnic minority terms

Funding No funding was received for this article.

Data Availability The database is available from the corresponding author.

Code Availability Not applicable.

\section{Declarations}

Conflict of interest The authors declare that there are no conflicts of interest.

Informed consent No human subject was involved in this study.

\section{References}

Adler, N. E., \& Rehkopf, D. H. (2008). U.S. disparities in health: Descriptions, causes, and mechanisms. Annual Review of Public Health. https://doi.org/10.1146/annurev.publhealth.29.020907. 090852

Akinbami, L. J., Vuong, N., Petersen, L. R., Sami, S., Patel, A., Lukacs, S. L., Mackey, L., Grohskopf, L. A., Shehu, A., \& Atas, J. (2020). SARS-CoV-2 seroprevalence among healthcare, first response, and public safety personnel, detroit metropolitan area, Michigan, USA, May-June 2020. Emerging Infectious Diseases, 26(12), 2863. https://doi.org/10.3201/EID2612.203764

Alamo-Pastrana, C., \& Hoynes, W. (2020). Racialization of news: constructing and challenging professional journalism as "White Media." Humanity \& Society. https://doi.org/10.1177/0160597618 820071
Amzel, A., \& Ghosh, C. (2007). National newspaper coverage of minority health disparities. Journal of the National Medical Association. https://doi.org/10.13016/boit-lj6u

Balan, D. J., DeGraba, P., \& Wickelgren, A. L. (2011). Ideological Persuasion in the Media. SSRN Electronic Journal. https://doi. org/10.2139/ssrn.637304

Baron, D. P. (2006). Persistent media bias. Journal of Public Economics. https://doi.org/10.1016/j.jpubeco.2004.10.006

Basu, A., \& Dutta, M. J. (2009). Sex workers and HIV/AIDS: Analyzing participatory culture-centered health communication strategies. Human Communication Research. https://doi.org/10.1111/j. 1468-2958.2008.01339.x

Baum, M. A. (2011). Red state, blue state, flu state: Media Self-Selection and Partisan Gaps in Swine Flu Vaccinations. Journal of Health Politics, Policy and Law. https://doi.org/10.1215/03616 878-1460569

Bhopal, R. (2004). Glossary of terms relating to ethnicity and race: For reflection and debate. Journal of Epidemiology and Community Health. https://doi.org/10.1136/jech.2003.013466

Bleich, S. N., Jarlenski, M. P., Bell, C. N., \& Laveist, T. A. (2012). Health inequalities: Trends, progress, and policy. Annual Review of Public Health. https://doi.org/10.1146/annurev-publh ealth-031811-124658

Booske, B. C., Robert, S. A., \& Rohan, A. M. K. (2011). Awareness of racial and socioeconomic health disparities in the united states: The national opinion survey on health and health disparities, 2008-2009. Preventing Chronic Disease. https://doi.org/10. 13016/i0vg-i0e2

Brodie, M., Kjellson, N., Hoff, T., \& Parker, M. (1999). Perceptions of latinos, african americans, and whites on media as a health information source. Howard Journal of Communications, 10(3), 147-167. https://doi.org/10.1080/106461799246799

Caburnay, C. A., Kreuter, M. W., Cameron, G., Luke, D. A., Cohen, E. L., McDaniels, L., Wohlberg, M., \& Atkins, P. (2008) Black newspapers as a tool for cancer education in African American communities. Ethnicity and Disease.

CDC. (2009) What We Know About Health Literacy.

CDC. (2016) CDC Health Disparities \& Inequalities Report (CHDIR) - Minority Health - CDC. CDC Health Disparities \& Inequalities Report (CHDIR)

CDC. (2020) COVID-19 Hospitalization and Death by Race/Ethnicity. CDC

Chowkwanyun, M., \& Reed, A. L. (2020). Racial health disparities and Covid-19 - caution and context. New England Journal of Medicine. https://doi.org/10.1056/nejmp2012910

Cohen, E. L., Caburnay, C. A., Luke, D. A., Rodgers, S., Cameron, G. T., \& Kreuter, M. W. (2008). Cancer coverage in general-audience and black newspapers. Health Communication. https://doi.org/10. 1080/10410230802342176

COVID-19 Dashboard. (2020) Johns Hopkins University Coronavirus Resrouce Center

Crossley, S. A., Skalicky, S., Dascalu, M., McNamara, D. S., \& Kyle, K. (2017). Predicting text comprehension, processing, and familiarity in adult readers: new approaches to readability formulas. Discourse Processes. https://doi.org/10.1080/0163853X.2017. 1296264

D’Alessandro, D. M., Kingsley, P., \& Johnson-West, J. (2001). The readability of pediatric patient education materials on the world wide web. Archives of Pediatrics and Adolescent Medicine. https://doi.org/10.1001/archpedi.155.7.807

Dalecki, L., Lasorsa, D. L., \& Lewis, S. C. (2009). The news readability problem. Journalism Practice. https://doi.org/10.1080/17512 780802560708

Daraz, L., Morrow, A. S., Ponce, O. J., Farah, W., Katabi, A., Majzoub, A., Seisa, M. O., Benkhadra, R., Alsawas, M., Larry, P., \& Murad, 
M. H. (2018). Readability of Online Health Information: A MetaNarrative Systematic Review. American Journal of Medical Quality. https://doi.org/10.1177/1062860617751639

Eltorai, A., Ghanian, S., Adams, C., Born, C., \& Daniels, A. (2014). Readability of patient education materials on the american association for surgery of trauma website. Archives of Trauma Research. https://doi.org/10.5812/atr.18161

Everyday Words for Public Health Communication. (2016). Centers for Disease Control and Prevention.

First Travel-related Case of 2019 Novel Coronavirus Detected in United States. (2020). Centers for Disease Control and Prevention

Freidman, D. B., \& Tanner, A. (2007). Reading difficulty level of medical resources on television Web sites: recommendations for a social practices approach to consumer health literacy. Journal of Consumer Health on the Internet. https://doi.org/10.1300/J381v 11n04_04

French, K. S., \& Larrabee, J. H. (1999). Relationships among educational material readability, client literacy, perceived beneficence, and perceived quality. Journal of Nursing Care Quality. https:// doi.org/10.1097/00001786-199908000-00008

Gentzkow, M. A., \& Shapiro, J. M. (2011). What Drives Media Slant? Evidence from U.S. Daily Newspapers. SSRN Electronic Journal. https://doi.org/10.2139/ssrn.947640

Gollust, S. E., \& Cappella, J. N. (2014). Understanding public resistance to messages about health disparities. Journal of Health Communication. https://doi.org/10.1080/10810730.2013.821561

Gollust, S. E., Lantz, P. M., \& Ubel, P. A. (2009). The polarizing effect of news media messages about the social determinants of health. American Journal of Public Health. https://doi.org/10.2105/ AJPH.2009.161414

Gollust, S. E., Vogel, R. I., Rothman, A., Yzer, M., Fowler, E. F., \& Nagler, R. H. (2020). Americans' perceptions of disparities in COVID-19 mortality: Results from a nationally-representative survey. Preventive Medicine. https://doi.org/10.1016/j.ypmed. 2020.106278

Groeling, T. (2013). Media Bias by the Numbers: Challenges and Opportunities in the Empirical Study of Partisan News. Annual Review of Political Science. https://doi.org/10.1146/annurev-polis ci-040811-115123

Hilligoss, B., \& Rieh, S. Y. (2008). Developing a unifying framework of credibility assessment: Construct, heuristics, and interaction in context. Information Processing and Management. https://doi. org/10.1016/j.ipm.2007.10.001

Hu, L., \& Kearney, M. (2019). healthforum: Scrape Patient Forum Data.

Huang, X., Li, Z., Lu, J., Wang, S., Wei, H., \& Chen, B. (2020). Timeseries clustering for home dwell time during COVID-19: What can we learn from it? ISPRS International Journal of Geo-Information, 9(11), 675. https://doi.org/10.3390/ijgi9110675

Huang, X., Lu, J., Gao, S., Wang, S., Liu, Z., \& Wei, H. (2021). Staying at Home Is a Privilege: Evidence from fine-grained mobile phone location data in the united states during the COVID-19 pandemic. Annals of the American Association of Geographers. https://doi. org/10.1080/24694452.2021.1904819

Kao, D. T. (2013). The impacts of goal orientation, terminology effect, and source credibility on communication effectiveness. Journal of Applied Social Psychology. https://doi.org/10.1111/jasp.12154

Kim, A. E., Kumanyika, S., Shive, D., Igweatu, U., \& Kim, S. H. (2010). Coverage and framing of racial and ethnic health disparities in US newspapers, 1996-2005. American Journal of Public Health. https://doi.org/10.2105/AJPH.2009.171678

Larcinese, V., Puglisi, R., \& Snyder, J. M. (2011). Partisan bias in economic news: Evidence on the agenda-setting behavior of US newspapers. Journal of Public Economics. https://doi.org/10. 1016/j.jpubeco.2011.04.006
Lin, C. A. (2020). A year like no other a call to curb the infodemic and depoliticize a pandemic crisis. Journal of Broadcasting and Electronic Media, 64(5), 661-671. https://doi.org/10.1080/08838 151.2020.1871185

Lin, C. A., \& Lagoe, C. (2013). Effects of news media and interpersonal interactions on $\mathrm{H} 1 \mathrm{~N} 1$ risk perception and vaccination intent. Communication Research Reports. https://doi.org/10.1080/08824 096.2012.762907

Lin, C. A., Neafsey, P. J., \& Strickler, Z. (2009). Usability testing by older adults of a computer-mediated health communication program. Journal of Health Communication, 14(2), 102-118. https:// doi.org/10.1080/10810730802659095

Lin, L., Savoia, E., Agboola, F., \& Viswanath, K. (2014). What have we learned about communication inequalities during the H1N1 pandemic: A systematic review of the literature. BMC Public Health. https://doi.org/10.1186/1471-2458-14-484

Lumpkins, C. Y., Bae, J., \& Cameron, G. T. (2010). Generating conflict for greater good: Utilizing contingency theory to assess Black and mainstream newspapers as public relations vehicles to promote better health among African Americans. Public Relations Review. https://doi.org/10.1016/j.pubrev.2009.08.010

Luo, Y., Burley, H., Moe, A., \& Sui, M. (2019). A Meta-Analysis of News Media's Public Agenda-Setting Effects, 1972-2015. Journalism and Mass Communication Quarterly, 96(1), 150. https:// doi.org/10.1177/1077699018804500

McLaughlin, G. (1969). SMOG grading-A new readability formula. Journal of Reading, 12, 639-646.

Medicine, I. of. (2004). Health Literacy: A Prescription to End Confusion (L. Nielsen-Bohlman, A. M. Panzer, \& D. A. Kindig (Eds.)). The National Academies Press. https://doi.org/10. $17226 / 10883$

Merkley, E. (2019). Partisan Bias in Economic News Content: New Evidence. American Politics Research. https://doi.org/10.1177/ $1532673 X 18821954$

Metzger, M. J., \& Flanagin, A. J. (2013). Credibility and trust of information in online environments: The use of cognitive heuristics. Journal of Pragmatics. https://doi.org/10.1016/j.pragma.2013. 07.012

Nagler, R. H., Bigman, C. A., Ramanadhan, S., Ramamurthi, D., \& Viswanath, K. (2016). Prevalence and framing of health disparities in local print news: Implications for multilevel interventions to address cancer inequalities. Cancer Epidemiology Biomarkers and Prevention. https://doi.org/10.1158/1055-9965.EPI-15-1247

Niederdeppe, J., Bigman, C. A., Gonzales, A. L., \& Gollust, S. E. (2013). Communication About Health Disparities in the Mass Media. Journal of Communication. https://doi.org/10.1111/jcom. 12003

NIH. (2016) Clear \& Simple-Step 3: Develop a Concept for the Product. NIH Office of Communications and Public Liaison

Nørregaard, J., Horne, B. D., \& Adal1, S. (2019). NELA-GT-2018: A large multi-labelled news dataset for the study of misinformation in news articles. Proceedings of the 13th International Conference on Web and Social Media, ICWSM 2019.

Paek, H. J., Yoon, S. H., \& Shah, D. V. (2005). Local news, social integration, and community participation: Hierarchical linear modeling of contextual and cross-level effects. Journalism and Mass Communication Quarterly. https://doi.org/10.1177/10776 9900508200307

People. (2010). Healthy People 2020 Objective Topic Areas and Page Numbers Healthy People 2020 Summary of Objectives Access to Health Services. Health San Francisco. https://doi.org/10.1371/ journal.ppat.1002074

Pew Research Center. (2017). The Partisan Divide on Political Values Grows Even Wider

Pew Research Center. (2020). U.S. Media Polarization and the 2020 Election: A Nation Divided. Pew Research Centre 
Puglisi, R., \& Snyder, J. M. (2011). Newspaper coverage of political scandals. Journal of Politics. https://doi.org/10.1017/S002238161 1000569

Rayner, K., Slattery, T. J., Drieghe, D., \& Liversedge, S. P. (2011). Eye Movements and Word Skipping During Reading: Effects of Word Length and Predictability. Journal of Experimental Psychology: Human Perception and Performance. https://doi.org/10. 1037/a0020990

Rock, M. (2005). Diabetes portrayals in North American print media: A qualitative and quantitative analysis. American Journal of Public Health. https://doi.org/10.2105/AJPH.2004.049866

Ronald, D., \& Morial, M. (2020). The covid-19 racial disparities could be even worse than we think. The Washington Post

Sakai, Y. (2013). The role of readability in effective health communication: An experiment using a Japanese health information text on chronic suppurative otitis media. Health Information and Libraries Journal. https://doi.org/10.1111/hir.12022

Scheufele, D. A., Shanahan, J., \& Kim, S. H. (2002). Who cares about local politics? Media influences on local political involvement, issue awareness, and attitude strength. Journalism and Mass Communication Quaterly. https://doi.org/10.1177/107769900207900 211

Shearer, E. (2020). Local news is playing an important role for Americans during COVID-19 outbreak. Pew Research Center

Stefanov, P., Darwish, K., Atanasov, A., \& Nakov, P. (2020). Predicting the Topical Stance and Political Leaning of Media using Tweets. https://doi.org/10.18653/v1/2020.acl-main.50

Stossel, L. M., Segar, N., Gliatto, P., Fallar, R., \& Karani, R. (2012). Readability of patient education materials available at the point of care. Journal of General Internal Medicine, 27(9), 1165. https:// doi.org/10.1007/s11606-012-2046-0

Stryker, J. E., Fishman, J., Emmons, K. M., \& Viswanath, K. (2009). Cancer risk communication in mainstream and ethnic newspapers. Preventing Chronic Disease.

Sundar, S. S. (2008). The MAIN model: A heuristic approach to understanding technology effects on credibility. Digital Media, Youth, and Credibility. https://doi.org/10.1162/dmal.9780262562324.073

Tausczik, Y. R., \& Pennebaker, J. W. (2010). The psychological meaning of words: LIWC and computerized text analysis methods. Journal of Language and Social Psychology. https://doi.org/10. 1177/0261927X09351676

Taylor-Clark, K. A., Mebane, F. E., SteelFisher, G. K., \& Blendon, R. J. (2007). News of disparity: Content analysis of news coverage of African American healthcare inequalities in the USA, 1994-2004. Social Science and Medicine. https://doi.org/10.1016/j.socscimed. 2007.03.039

Tchuenche, J. M., \& Bauch, C. T. (2012). Dynamics of an infectious disease where media coverage influences transmission. ISRN Biomathematics. https://doi.org/10.5402/2012/581274

Thomson, M. D., \& Hoffman-Goetz, L. (2007). Readability and cultural sensitivity of web-based patient decision aids for cancer screening and treatment: A systematic review. Informatics for Health and Social Care. https://doi.org/10.1080/14639230701780408

U.S. Census Bureau. (2019). QuickFacts.

Viswanath, K., \& Emmons, K. M. (2006). Message effects and social determinants of health: Its application to cancer disparities. Journal of Communication. https://doi.org/10.1111/j.1460-2466.2006. 00292.x

Viswanath, K., Kosicki, G. M., Fredin, E. S., \& Park, E. (2000). Local community ties, community-boundedness, and local public affairs knowledge gaps. Communication Research. https://doi.org/10. $1177 / 009365000027001002$

Walsh, T. M., \& Volsko, T. (2008). Readability assessment of internetbased consumer health information. Respiratory Care. https://doi. org/10.1103/PhysRevD.10.1680

Wang, L. W., Miller, M. J., Schmitt, M. R., \& Wen, F. K. (2013). Assessing readability formula differences with written health information materials: Application, results, and recommendations. Research in Social and Administrative Pharmacy. https://doi.org/ 10.1016/j.sapharm.2012.05.009

$\mathrm{Xu}, \mathrm{Z}$. (2020). I don't understand you but I trust you: Using computer-aided text analysis to examine medical terminology use and engagement of vaccine online articles. Journal of Communication in Healthcare. https://doi.org/10.1080/17538068.2020.1755137

Xu, Z., Ellis, L., \& Laffidy, M. (2020). News frames and news exposure predicting flu vaccination uptake: Evidence from US Newspapers, 2011-2018 Using Computational Methods. Health Communication. https://doi.org/10.1080/10410236.2020.1818958

Xu, Z., Ellis, L., \& Umphrey, L. R. (2019). The Easier the Better? Comparing the Readability and Engagement of Online Pro- and Anti-Vaccination Articles. Health Education and Behavior. https://doi.org/10.1177/1090198119853614

Yoo, B. K., Holland, M. L., Bhattacharya, J., Phelps, C. E., \& Szilagyi, P. G. (2010). Effects of mass media coverage on timing and annual receipt of influenza vaccination among medicare elderly. Health Services Research. https://doi.org/10.1111/j.1475-6773.2010. 01127. $\mathrm{x}$

Zanolli, L. (2020). Data from US south shows African Americans hit hardest by Covid-19. The Guardian.

Zheng, J., \& Yu, H. (2017). Readability formulas and user perceptions of electronic health records difficulty: A corpus study. Journal of Medical Internet Research, 19(3), 59. https://doi.org/10.2196/ jmir.6962

Publisher's Note Springer Nature remains neutral with regard to jurisdictional claims in published maps and institutional affiliations. 